\title{
Microstructure, Mechanical Properties and Die-Filling Behavior of High-Performance Die-Cast Al-Mg-Si-Mn Alloy
}

\author{
Zu-Qi Hu ${ }^{1} \cdot$ Xin-Jian Zhang ${ }^{1} \cdot$ Shu-Sen $\mathrm{Wu}^{2}$
}

Received: 8 July 2015/Revised: 15 September 2015/Published online: 14 November 2015

(C) The Chinese Society for Metals and Springer-Verlag Berlin Heidelberg 2015

\begin{abstract}
This work aims to reveal the relationships between the microstructure, mechanical properties and flow behavior of die-casting $\mathrm{AlMg}_{5} \mathrm{Si}_{2} \mathrm{Mn}$ alloy. Results indicated that the microstructure of the die-cast $\mathrm{AlMg}_{5} \mathrm{Si}_{2} \mathrm{Mn}$ consists of $\alpha_{1}-\mathrm{Al}$ grains, fine-size $\alpha_{2}-\mathrm{Al}$ grains and $\left(\mathrm{Al}+\mathrm{Mg}_{2} \mathrm{Si}\right)$ eutectic. The surface layer observed has the thickness in a range of 120-135 $\mu \mathrm{m}$, while an ellipse-like surface layer edge is observed in the corner of the plate-like sample. Tensile strength and elongation $(\delta)$ of the specimens are slightly decreased along the die-filling direction due to the backflow of melt. Pure $\left(\mathrm{Al}+\mathrm{Mg}_{2} \mathrm{Si}\right.$ ) eutectic layer and ultra-fine-size $\alpha_{2}-\mathrm{Al}$ grains observed are around the overflow channels. Mass feeding is predominantly responsible for the superior mechanical properties of the round bars as compared to those of plate-like samples.
\end{abstract}

KEY WORDS: High-pressure die casting; Aluminum alloy; Microstructure segregations; Mechanical properties; Die-filling behavior; Numerical simulation

\section{Introduction}

In recent years, high-pressure die casting (HPDC) has been widely adopted in rising automotive industry and the components are increasingly used due to their excellent surface quality, dimensional accuracy and integrity [1]. Even though the high porosity deteriorates the ductility and fatigue resistance of die castings, they are still urgently expected to be used as high-duty structural components.

High-performance die-cast aluminum alloys have been developed to lighten the security components and maintain

Available online at http://link.springer.com/journal/40195

Xin-Jian Zhang

huzuqi@caep.cn

1 Institute of Materials, China Academy of Engineering Physics, Mianyang 621900, China

2 State Key Lab of Materials Processing and Die \& Mould Technology, Huazhong University of Science and Technology, Wuhan 430074, China their safety in dynamic loading situations [2]. $\mathrm{AlMg}_{5} \mathrm{Si}_{2} \mathrm{Mn}$ alloy possesses good elongation $(13 \%-17 \%)$ in as-cast condition and enables manufacturers to economically produce security components (e.g., suspension and shock tower) [3, 4]. Microstructure evolution and static mechanical properties of HPDC $\mathrm{AlMg}_{5} \mathrm{Si}_{2} \mathrm{Mn}$ alloy have been enthusiastically studied. For instance, Kaufmann et al. [5] reported that $\mathrm{AlMg}_{5} \mathrm{Si}_{2} \mathrm{Mn}$ alloy could be fabricated by forging, squeeze casting, rheocasting and die casting. Ji et al. [6] found that the elongation of 'super-ductile' diecast $\mathrm{Al}$ alloy $\left(\mathrm{AlMg}_{5} \mathrm{Si}_{1.5} \mathrm{MnFe}_{0.25}\right)$ was reduced as the $\mathrm{Si}$, $\mathrm{Cu}$ and $\mathrm{Fe}$ contents increased. However, the chemical composition of the alloy is similar to $\mathrm{AlMg}_{5} \mathrm{Si}_{2} \mathrm{Mn}$. Otarawanna et al. [7-9] demonstrated that the liquid metals with distinct solid fractions interact with each other, which resulted in the formation of surface skins and defect bands.

In addition, high-vacuum die-casting (HVDC) technology has been developed to eliminate the porosity and facilitate the die-filling process [10]. Niu et al. [11] reported that the tensile properties of HVDC Al-Si specimens were superior to those of HPDC specimens. Hébert 
et al. [12] documented that the fatigue limits of HVDC Al$10 \% \mathrm{Si}-\mathrm{Mg}$ specimen (139 MPa) is substantially higher than that of HPDC specimen (107 MPa). Moreover, Jin et al. [13] concluded that the surface quality, heat treatability and porosity of $\mathrm{HVDC} \mathrm{Al}-10 \mathrm{Si}-0.4 \mathrm{Mg}$ bipolar plates were superior to those of HPDC samples, whereas the effect of the vacuum assistance on the mechanical properties of $\mathrm{HPDC} \mathrm{AlMg}_{5} \mathrm{Si}_{2} \mathrm{Mn}$ alloy has been rarely reported.

Previous researches have focused on the mechanical properties and the microstructure formation of HPDC $\mathrm{AlMg}_{5} \mathrm{Si}_{2} \mathrm{Mn}$ alloy, and little attention has been paid to the relationships between the microstructure segregation, the mechanical properties and die-filling behavior of the alloy. In order to broaden the application of $\mathrm{AlMg}_{5} \mathrm{Si}_{2} \mathrm{Mn}$ in automotive industry and reduce the fuel consumption, the current work aims to reveal these relationships through experiment-simulation approach.

\section{Experimental}

\subsection{Die Casting}

Plate samples and round testing bars shown in Fig. 1 were produced by horizontal cold-chamber die-casting machine. Self-developed vacuum valve (shown in Fig. 1c) was incorporated into the die, which maintained the vacuum degree inside the die cavity above $90 \mathrm{kPa}$. The ingate of the die-casting samples is as thick as $2 \mathrm{~mm}$. $\mathrm{Al}-\mathrm{Si}_{2}-\mathrm{Mn}$ ingots were melted in a graphite crucible of an electric resistance furnace, and the required amount of the pure magnesium was added into the melt when the temperature was $650{ }^{\circ} \mathrm{C}$. Then, the melt was degassed for 20 min with argon gas through a graphite lance. Die-casting parameters adopted in this experiment are listed in Table 1 , where $T_{\mathrm{d}}$ and $T_{\mathrm{m}}$ are temperatures of the die and melt, $P$ is injection pressure, $v_{1}$ and $v_{2}$ are slow and fast shot velocities, respectively.

\subsection{Tensile Tests and Materials}

Three types of the specimens for tensile tests were designed according to ISO 6892-1 for studying the effects of die-filling behavior, the vacuum assistance and the specimen geometry on the mechanical properties of HPDC $\mathrm{AlMg}_{5} \mathrm{Si}_{2} \mathrm{Mn}$ alloy. As shown in Fig. 2a, b, A-type tensile specimens were sectioned along the filling direction to characterize the localized tensile properties of HPDC plates. The B-type specimens shown in Fig. 2c were sectioned from the center part of the plates to characterize the overall typical properties of HPDC plates. C-type specimens were standard round bars with the diameter of the gauge length of $6.4 \mathrm{~mm}$ shown in Fig. $2 \mathrm{~d}$. Tensile tests were carried out by electronic universal testing machine under ambient temperature, and the loading rate is $5 \mathrm{~mm} / \mathrm{min}$. Elongation was obtained by a knife-edge extensometer fixed in the range of the gauge length.

Chemical compositions of $\mathrm{Al}-\mathrm{Mg}-\mathrm{Si}-\mathrm{Mn}$ alloys were obtained by the optical emission spectroscopy analysis method, and the results are listed in Table 2. Cross section of the HPDC plate samples was grinded, polished and then etched by Keller's etchant $(1 \% \mathrm{HF}+1.5 \% \mathrm{HCl}+$ $2.5 \% \mathrm{HNO}_{3}$ ) for $10-15 \mathrm{~s}$ subsequently.
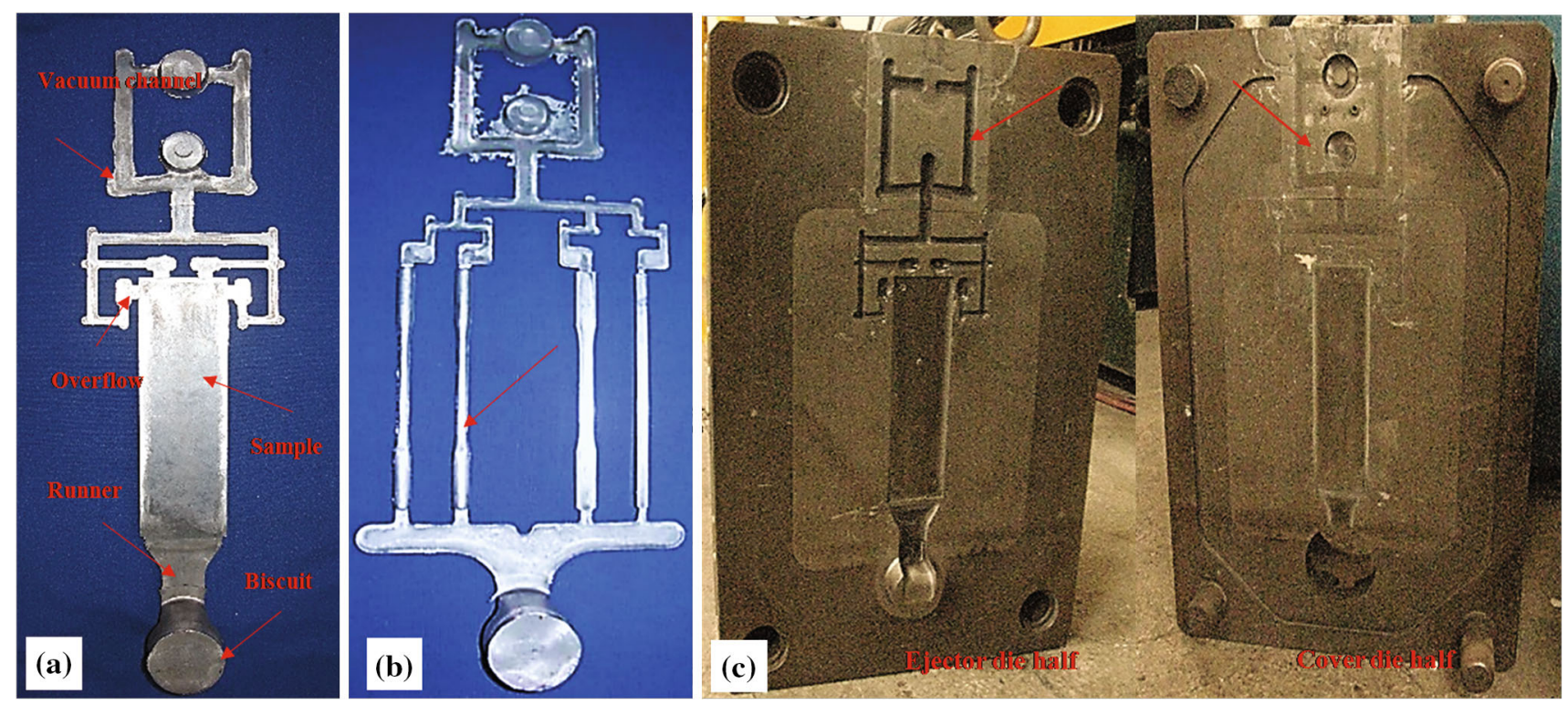

Fig. 1 a HPDC plates, b standard round tension test bar pointed by the arrow, c self-developed vacuum valve in the upside of the die 


\subsection{Flow-3D Simulation}

Simulations were carried out by Flow-3D software, and the modeling injection parameters were the same with those adopted in die-casting experiments. Simulation results were used to analyze the die-filling behavior and the localized tensile properties of die-cast plate samples. Flow3D software was based on the finite element method (FEM), and the total number of active cell counts is 948,883 . Thermal physical properties adopted in the simulations are listed in Table 3.

\section{Results}

\subsection{Typical Microstructures}

As shown in Fig. 3a, the typical microstructures of HPDC $\mathrm{AlMg}_{5} \mathrm{Si}_{2} \mathrm{Mn}$ alloy mainly contain $\alpha_{1}-\mathrm{Al}$ grains, $\alpha_{2}-\mathrm{Al}$

Table 1 Experimental die-casting parameters employed in current work

\begin{tabular}{lllll}
\hline$T_{\mathrm{d}}$ & $T_{\mathrm{m}}$ & $P$ & $v_{1}$ & $v_{2}$ \\
\hline $200{ }^{\circ} \mathrm{C}$ & $700-710{ }^{\circ} \mathrm{C}$ & $100 \mathrm{MPa}$ & $0.3 \mathrm{~m} / \mathrm{s}$ & $3 \mathrm{~m} / \mathrm{s}$
\end{tabular}

(a)

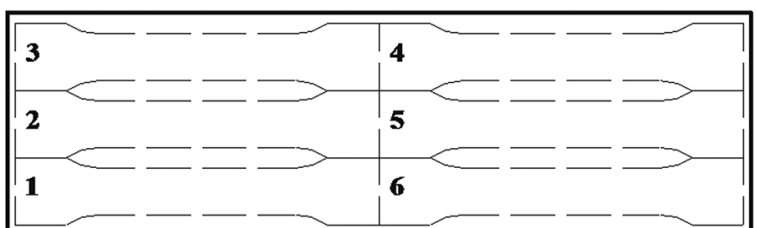

(c)

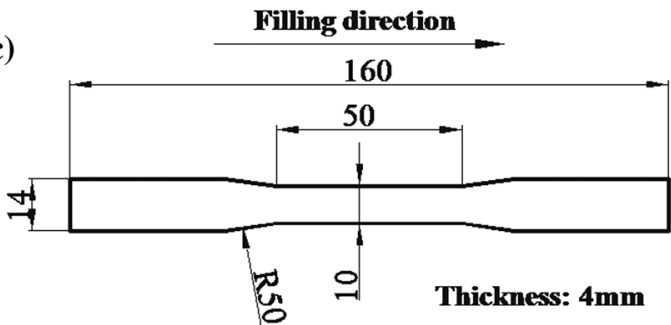

grains and $\left(\mathrm{Al}+\mathrm{Mg}_{2} \mathrm{Si}\right)$ eutectic regions. The $\alpha_{1}-\mathrm{Al}$ grains (externally solidified crystals, ESCs) initially nucleated in the shot sleeve as the molten alloy touched the wall of it. Therefore, the $\alpha_{1}-\mathrm{Al}$ crystals grow up during the entire injection process which resulted in their coarse size. As compared to the formation of $\alpha_{1}-\mathrm{Al}$ grains, fine-size $\alpha_{2}-\mathrm{Al}$ grains formed in an extremely high cooling rate due to the active heat transfer between the interface of the die walls and the casting. The dark region enclosed by the circle in Fig. $3 \mathrm{a}$ represents $\left(\mathrm{Al}+\mathrm{Mg}_{2} \mathrm{Si}\right)$ eutectic region which has a volume fraction of $29.6 \%$.

As shown in Fig. $3 b$, a surface layer is commonly observed in the plate samples, and its typical morphology is pointed by the solid arrow in Fig. 3b. The surface layer consists of fine-size $\alpha_{2}-\mathrm{Al}$ grains, spherical $\alpha_{1}-\mathrm{Al}$ grains and $\left(\mathrm{Al}+\mathrm{Mg}_{2} \mathrm{Si}\right)$ eutectic. The compact structure of the

Table 3 Thermal physical parameters adopted in simulations

\begin{tabular}{ll}
\hline Parameter & Value \\
\hline Latent heat of fusion & $4.95 \times 10^{9} \mathrm{~J} / \mathrm{g}$ \\
Solidification range & $813-898 \mathrm{~K}$ \\
Density & $2.5 \mathrm{~g} / \mathrm{cm}^{3}$ \\
Thermal conductivity of liquid & $1.88 \times 10^{7} \mathrm{~W} / \mathrm{m} \mathrm{K}$ \\
Specific heat & $1.153 \times 10^{7} \mathrm{~J} / \mathrm{kg} \mathrm{K}$
\end{tabular}

(b)
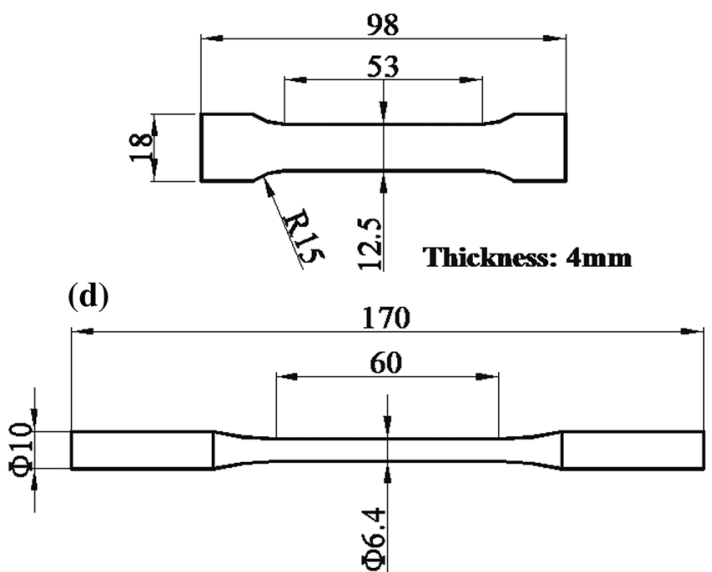

Fig. 2 Schematics of the tensile specimens (unit: $\mathrm{mm}$ ): a locations of the A-type tensile specimens, b A-type specimen, $\mathbf{c}$ B-type specimen, $\mathbf{d}$ Ctype specimen

Table 2 Chemical compositions of the different types of die-casting specimens (wt $\%$ )

\begin{tabular}{llllllll}
\hline Process & Specimen type & $\mathrm{Mg}$ & $\mathrm{Si}$ & $\mathrm{Mn}$ & $\mathrm{Fe}$ & $\mathrm{Ti}$ & $\mathrm{Al}$ \\
\hline HPDC/HVDC & $\mathrm{A}$ & 6.9 & 1.98 & 0.54 & 0.13 & 0.085 & $\mathrm{Bal}$ \\
HPDC & $\mathrm{B}$ & 5.7 & 1.94 & 0.57 & 0.16 & 0.09 & $\mathrm{Bal}$ \\
HPDC & $\mathrm{C}$ & 5.5 & 1.8 & 0.55 & 0.15 & 0.085 & $\mathrm{Bal}$ \\
\hline
\end{tabular}



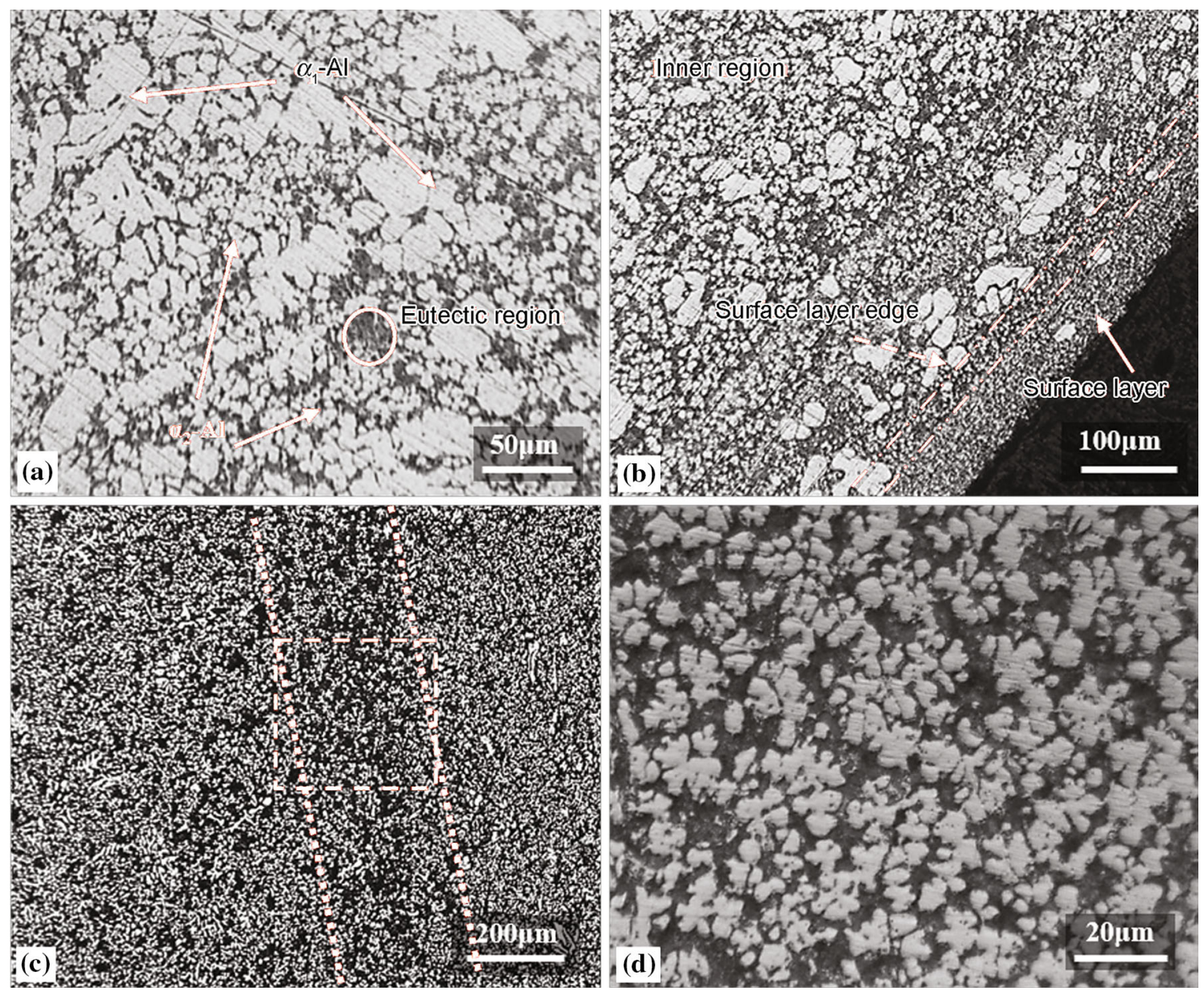

Fig. 3 Typical microstructures of the transverse cross section of HPDC $\mathrm{AlMg}_{5} \mathrm{Si}_{2} \mathrm{Mn}$ plate samples in different locations: a center part, b surface and subsurface, $\mathbf{c}$ dilatant shear band, $\mathbf{d}$ higher magnification of the dotted box in $\mathbf{c}$

surface layer provides good pressure tightness for die castings. The surface layer is demarcated from the inner region by surface layer edge (pointed by the dotted arrow in Fig. 3b). In surface layer edge, distribution of primary $\alpha_{2}-\mathrm{Al}$ grains is more uniform while coarse $\alpha_{1}-\mathrm{Al}$ grains almost disappeared.

As shown in Fig. 3c, d, volume fraction of $\left(\mathrm{Al}+\mathrm{Mg}_{2} \mathrm{Si}\right)$ eutectic in the shear bands is significantly higher than that in other areas; moreover, thickness of the shear band is about $200 \mu \mathrm{m}$. According to previous investigations [7, 9], the great external pressure leads to severe shear stress between the surface skin and the newly injected melt. The solid fraction $\left(f_{\mathrm{s}}\right)$ of melt continuously increased from the center part to the die walls during the solidification process. Since the liquid alloy with high $f_{\mathrm{s}}$ close to the die walls is impacted by the newly injected material with low $f_{\mathrm{s}}$, the interface is subjected to severe shear stress and the interspaces between the early solidified crystals are formed and expanded. Then, residual solute- enriched liquid is compressed into these interspaces and results in the high eutectic fraction of the shear bands.

\subsection{Microstructure Segregation}

Figure $4 \mathrm{a}$ shows the section line of the metallographic samples. Inner region, surface layer edge and surface layer of the microstructure near the upper die can be clearly identified (as shown in Fig. 4b). However, morphologies of the surface layer and surface layer edge shown in Fig. $4 \mathrm{~b}$ and Fig. $3 \mathrm{~b}$ are distinct. The surface layer in Fig. $4 \mathrm{~b}$ occupies the corner of the upper die, and the thickness decreases along the filling direction. The contour of the surface layer edge appears like an ellipse (shown in Fig. 4c), while the surface layer, surface layer edge and shear bands are absent near the gate (as shown in Fig. 4d).

Transverse cross-sectional area near the overflows is shown in Fig. 5a. As shown in Fig. 5b, c, the volume fraction of coarse ESCs in the overflow region is 


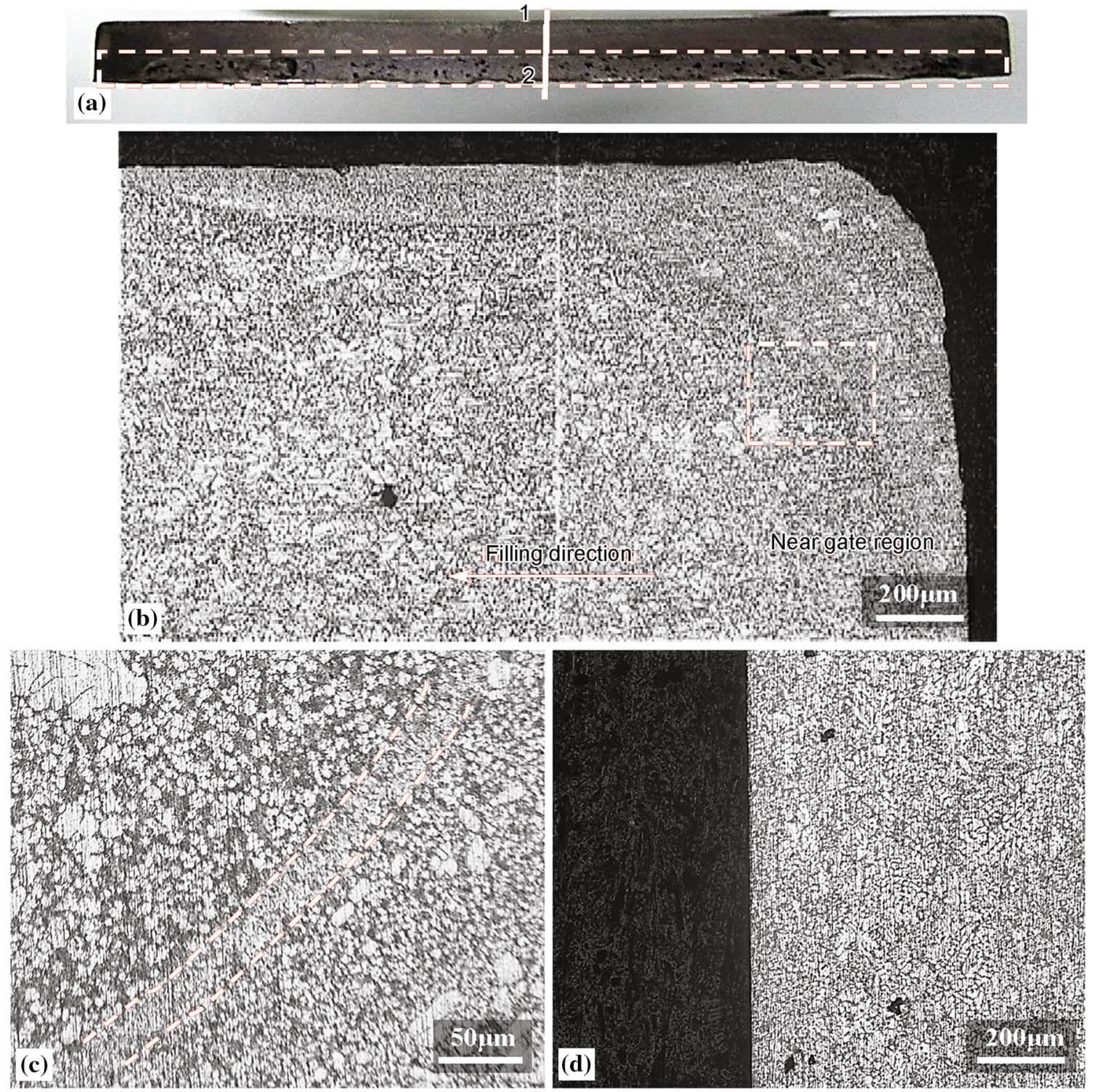

Fig. 4 Microstructures from the die-cast plates sectioned longitudinally: a inlet transverse of the castings showing the gate area (enclosed by the dotted box) and the die-filling direction heads into the page, $\mathbf{b}$ longitudinally cross-sectional area near the gate from the solid line in $\mathbf{a}, \mathbf{c}$ higher magnification of the dotted box in $\mathbf{b}$ and the surface layer edge is enclosed by the dotted lines, $\mathbf{d}$ longitudinally cross-sectional area around the line 2 in a

significantly higher than that in the plate sample region. Border is dominantly occupied by the primary $\alpha-\mathrm{Al}$ grains with much refined size (as shown in Fig. 5d), while the $\left(\mathrm{Al}+\mathrm{Mg}_{2} \mathrm{Si}\right.$ ) eutectic regions are almost absent in this area. Another characteristic microstructure morphology is observed in the area of line 2 and pointed by arrows in Fig. 5e. Besides the coarse dendritic ESCs and $\alpha_{2}-\mathrm{Al}$ grains, an about $50-\mu \mathrm{m}$-thick pure eutectic layer is observed at the bottom of the overflow.

\subsection{Tensile Properties}

Figure 6a indicates that the yield strengths $\left(\sigma_{0.2}\right)$ are insensitive to the section locations and vary in a narrow range (208-213 MPa), whereas the mean values of the ultimate tensile strengths $\left(\sigma_{\mathrm{m}}\right)$ and elongations $(\delta)$ of the groups of $1,2,3$ are $307.5 \mathrm{MPa}$ and $3.33 \%$, respectively, which are lower than those of the groups of 4, 5, 6 (327.5 MPa and 4.4\%). Therefore, the mechanical 


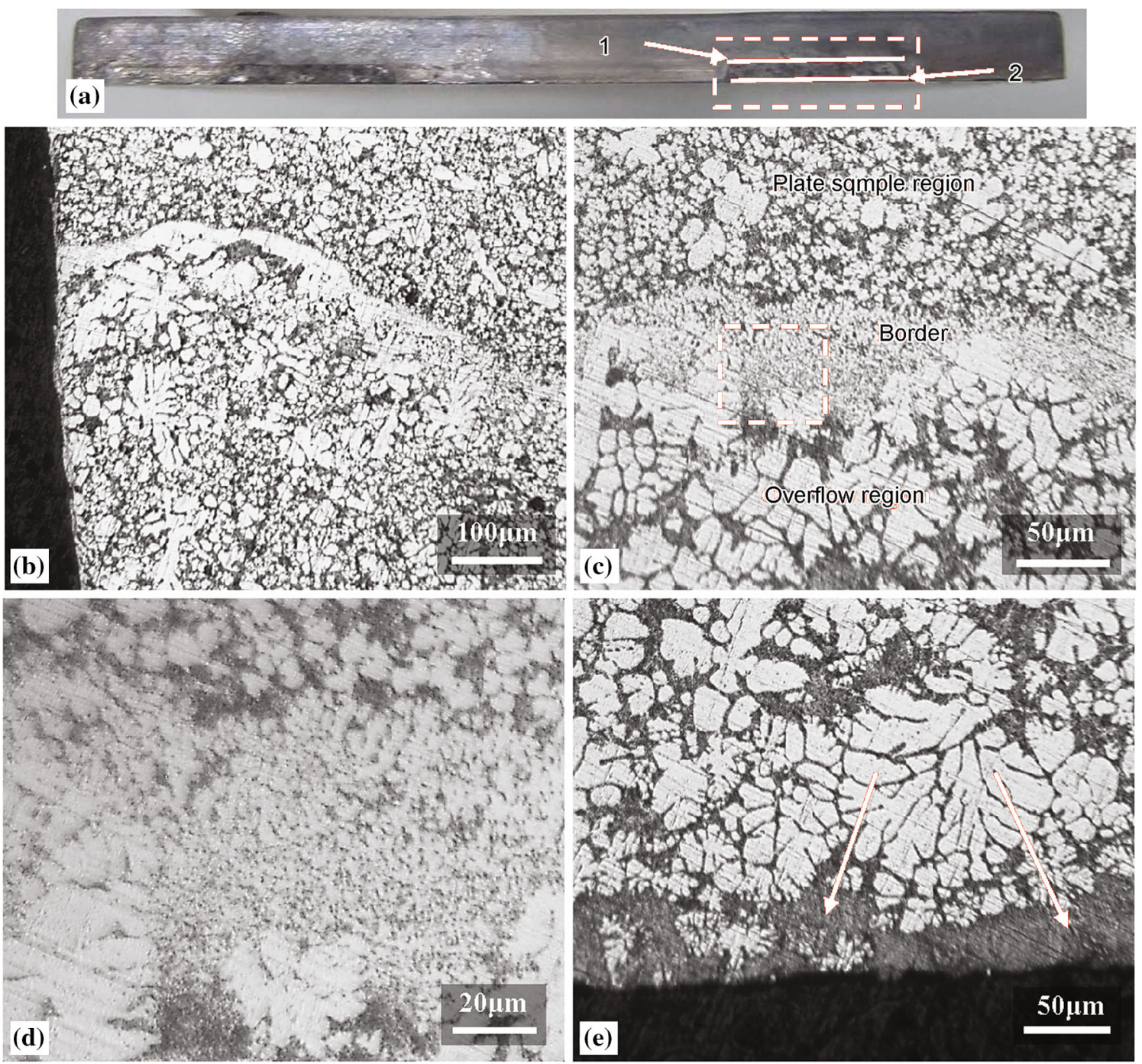

Fig. 5 Microstructure from the die-cast plates sectioned transversely: a transverse of the castings showing the overflows area (enclosed by the dotted box $)$ and the die-filling direction is out of the page, $\mathbf{b}$ corner of the cross-sectional area near the overflow from the line 1 in $\mathbf{a}, \mathbf{c}$ middle part of the cross-sectional area near the overflow from the line 1, $\mathbf{d}$ higher magnification of the dotted box in $\mathbf{c}, \mathbf{e}$ transversely cross-sectional area near the overflow from the line 2 in a and the regions pointed by the solid arrows represent the pure eutectic region

properties of the specimens sectioned near the overflows are superior to those sectioned near the ingate. As compared to previous investigations [6,14], the slightly lower elongation in this experiment can be attributed to the relatively higher magnesium content $(6.9 \%)$.

According to Fig. 6b, the tensile properties of HVDC plate samples $\left(\sigma_{\mathrm{m}}, \sigma_{0.2}, \delta\right)$ are slightly better than those of HPDC specimens. Increasing percentages of $\sigma_{\mathrm{m}}, \sigma_{0.2}$ and $\delta$ are 4.6, 2.8 and $22.4 \%$, respectively; thus, vacuum assistance substantially may improve the ductility of the alloy. Elongation of C-type specimen is $13.77 \%$ which is significantly higher than that of B-type specimens and can be ascribed to effective feeding mechanism of C-type specimens.

\subsection{Numerical Simulation}

Figure 7 interprets the die-filling behavior of the liquid alloy, and red color means the high-temperature melt to touch the bottom die. As the die cavity is $40 \%$ filled, the melt flows through the gate and preferentially along the lateral walls of the die (as shown in Fig. 7a). The melt (jet) front impacts on the upper die surface first and creates an unfilled cavity (enclosed by the dotted box in Fig. 7b). Area of the unfilled cavity is maximized as the die-filling degree is $60 \%$ as shown in Fig. 7c, and the melt flows reversely due to the opposite force provided by the die wall when the melt front advances to the overflows. As the unfilled cavity is continuously filled by the backflow, its 

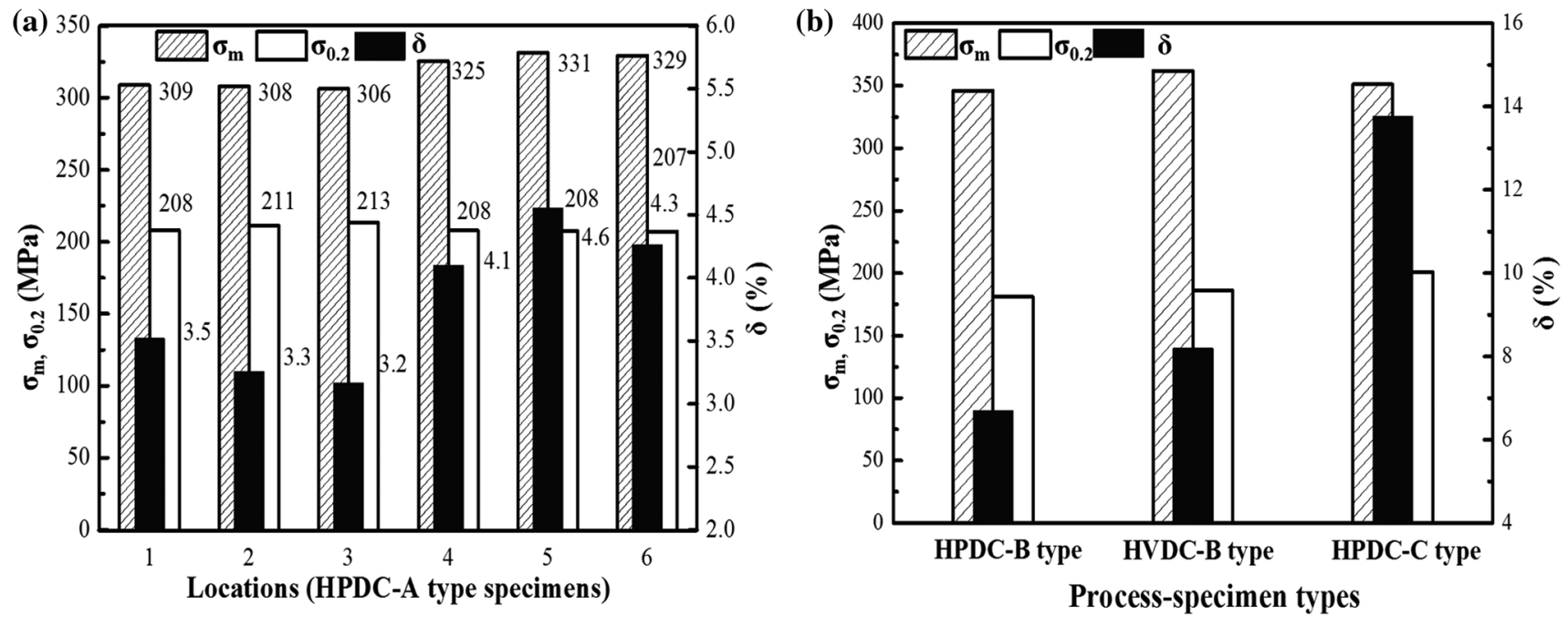

Fig. 6 Mechanical properties of the specimen section from different locations a and different specimen types $\mathbf{b}$

area is substantially decreased (as shown in Fig. 7d). The corner near the gate is filled by the backflow at last (as shown in Fig. 7e), and the vacuum channel is not completely filled as the die-filling degree is $80 \%$ (as shown in Fig. 7f). According to the simulation, the impurities and defects, such as oxides, cold flakes, pores, are probably detained near the ingate since they are unable to remove in the final stage of solidification. This could be responsible for the inferior mechanical properties of the specimens near the ingate.

\section{Discussion}

\subsection{Macrostructure/Microstructure Segregations and Die-Filling Behavior}

Ellipse-like surface layer edge shown in Fig. 5b can be explained by the melt flow behavior well. According to the simulation result shown in Fig. 7a, b, the melt (jet) first impacts on the position 3 of the upper die and position 2 of the bottom die (shown in Fig. 8a), which can be regarded as a direct impingement zone (DIZ) [15]. Both the surface layer and the surface layer edge are absent in DIZ because the liquid alloy near DIZ retains its high temperature and the early solidified crystal can be swept away from the die walls by the newly injected melt.

In contrary, because the crystal in position 1 is not directly impacted by such high velocity filling flow, it is indirection impingement zone (IIZ). The crystal in IIZ grows up in a more stable condition as compared to those formed in positions 2 and 3. Thus, a stagnant wall layer (as shown in Fig. 8b) formed in the corner due to the low temperature of the die walls [8]. Moreover, as the high- temperature melt moves across the stagnant wall layer, the solute-enriched liquid with hypoeutectic composition is squeezed into the border between the surface layer and inner region through the flow channels, which results in the formation of ellipse-like surface layer edge.

According to the study of Chen [15], thickness of the surface layer formed in IIZ away from the stagnant wall layer is affected by the external pressure during intensification stage and can be calculated by Eq. (1):

$S=h \cdot t \cdot \frac{T_{\mathrm{A}}-T_{\mathrm{D}}}{\rho H}$,

where $S$ is the solidified thickness, $h$ is the heat transfer coefficient, $t$ is the solidification time, $H$ is the latent heat of solidification, $T_{\mathrm{A}}$ is the main eutectic solidification temperature, and $T_{\mathrm{D}}$ is the die temperature for shot. In this work, $\rho=2650 \mathrm{~kg} / \mathrm{cm}^{3}, \quad H=495 \mathrm{~kJ} / \mathrm{kg}, \quad t=0.15 \mathrm{~s}$, $h=6 \mathrm{~kW} / \mathrm{m}^{2} \mathrm{~K}, T_{\mathrm{D}}=573 \mathrm{~K}$ and $T_{\mathrm{A}}=873 \mathrm{~K}$ are adopted according to previous researches [16] and $\mathrm{Al}-\mathrm{Mg}-\mathrm{Si}$ phase diagrams [17]. The calculated result shows that $S$ is $205 \mu \mathrm{m}$, and the measurement values of $S$ from Fig. 5b and Fig. $3 \mathrm{~b}$ are in the range of $120-135 \mu \mathrm{m}$; therefore, the calculation results are in agreement with that of experimental to some extent.

Microstructural segregation shown in Fig. 5 was rarely reported, and the pure $\left(\mathrm{Al}+\mathrm{Mg}_{2} \mathrm{Si}\right)$ eutectic layer is exclusively observed around the overflow. Figure $7 \mathrm{c}$ indicates that the melt front reaches the overflow channel as the die-filling degree is $60 \%$. Solid fraction of the melt front is high (as shown in Fig. 9a) due to the long flowing distance $(\approx 200 \mathrm{~mm}$ ) and the great heat loss of the melt. Therefore, numerous coarse ESCs start to block the inlet of the overflows due to the small cross-sectional area and the poor fluidity of melt (as shown in Fig. 9b). As shown in Fig. 9c, 
(a)

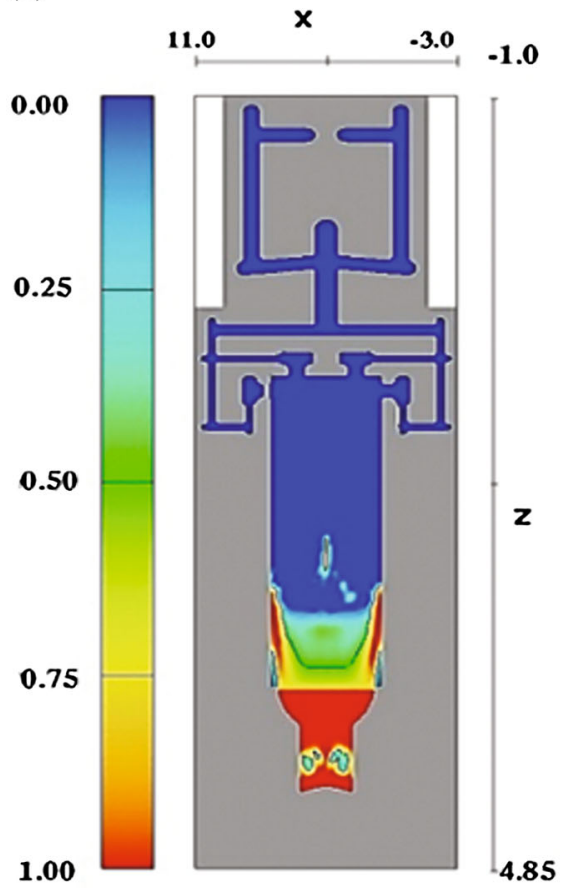

(d)

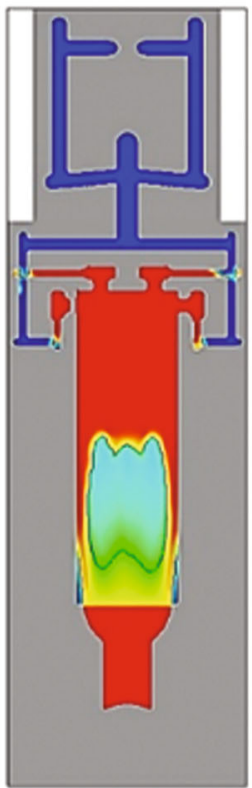

(b)

Fraction of fluid contours

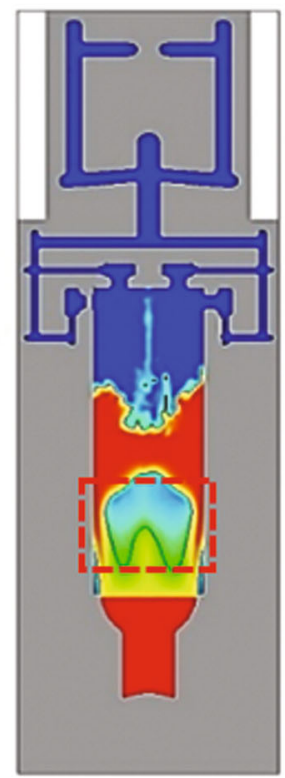

(e)

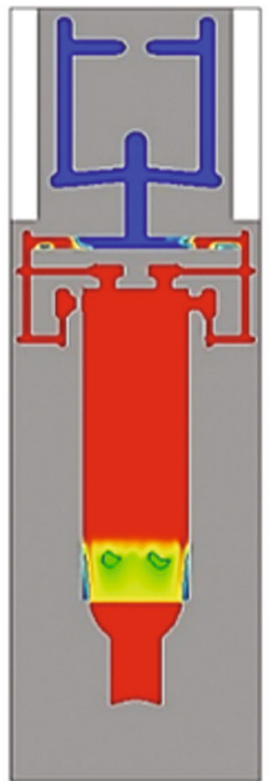

(c)

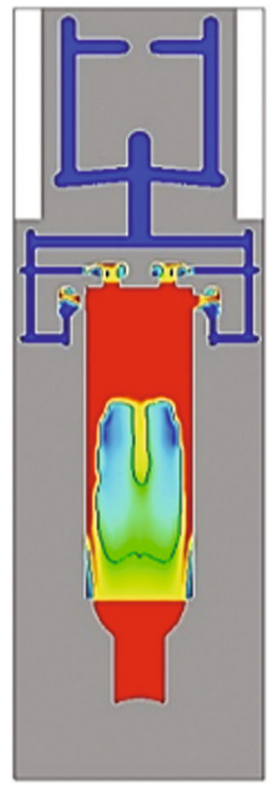

(f)

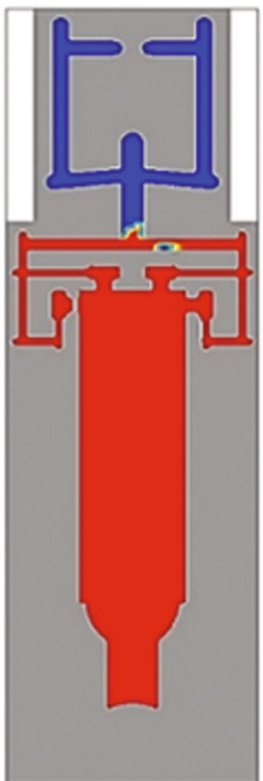

Fig. 7 Simulation results of the contour of liquid alloy at different die-filling degrees: a $40 \%$, b 50\%, c $60 \%$, d $65 \%$, e $75 \%$, f $80 \%$

the primary $\alpha_{2}-\mathrm{Al}$ crystal is preferentially solidified around the inlet of the overflow which further increases the local $f_{\mathrm{s}}$ and compresses subsequently coming liquid toward the upper die.

Dahle et al. [18] have documented that the solidifying material starts to have strength and transmit shear stress as the solid fraction of melt is above $f_{\text {coh }}$ (coherent solid fraction) and the dendrite is connected to each other.
Therefore, solid fraction plays a vital role in the shear stress delivery and the formation of localized microstructure. In current work, the melt in the adjacent region of the overflow channel and vertical die wall (enclosed by the circle in Fig. 9c) is subjected to severe shear stress, which may be induced by the external pressure during the intensification stage. Finally, the shear stress results in the extremely fine-size $\alpha-\mathrm{Al}$ crystal shown in Fig. 5c, d. 
(a) During solidification

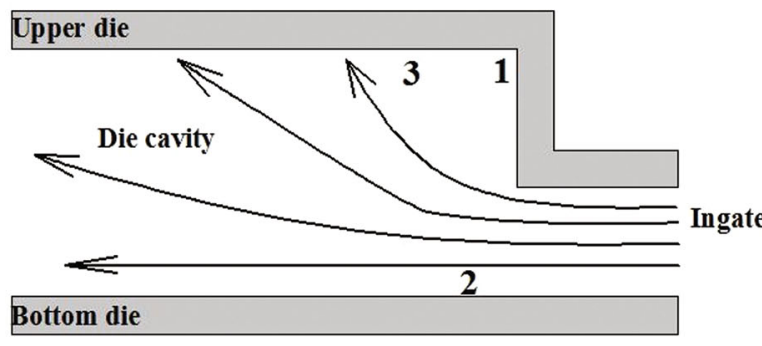

Die walls $\longleftarrow$ Melt flow direction

\section{(b) Solidification completed}

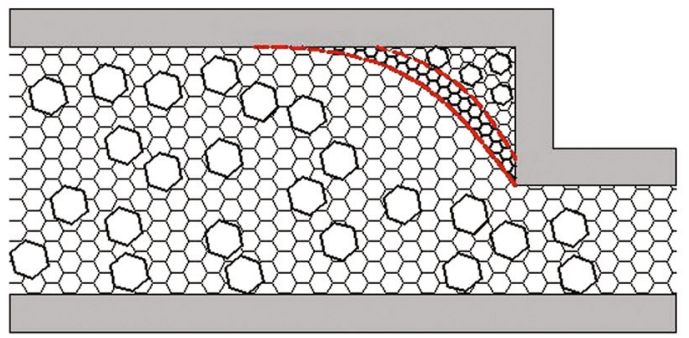

$\alpha_{1}$-Al grains (ESCs) $\quad \alpha_{2}$-Al grains

Fig. 8 Schematics of the formation of the ellipse-like surface layer edge: a melt flow during solidification, b microstructures in different locations
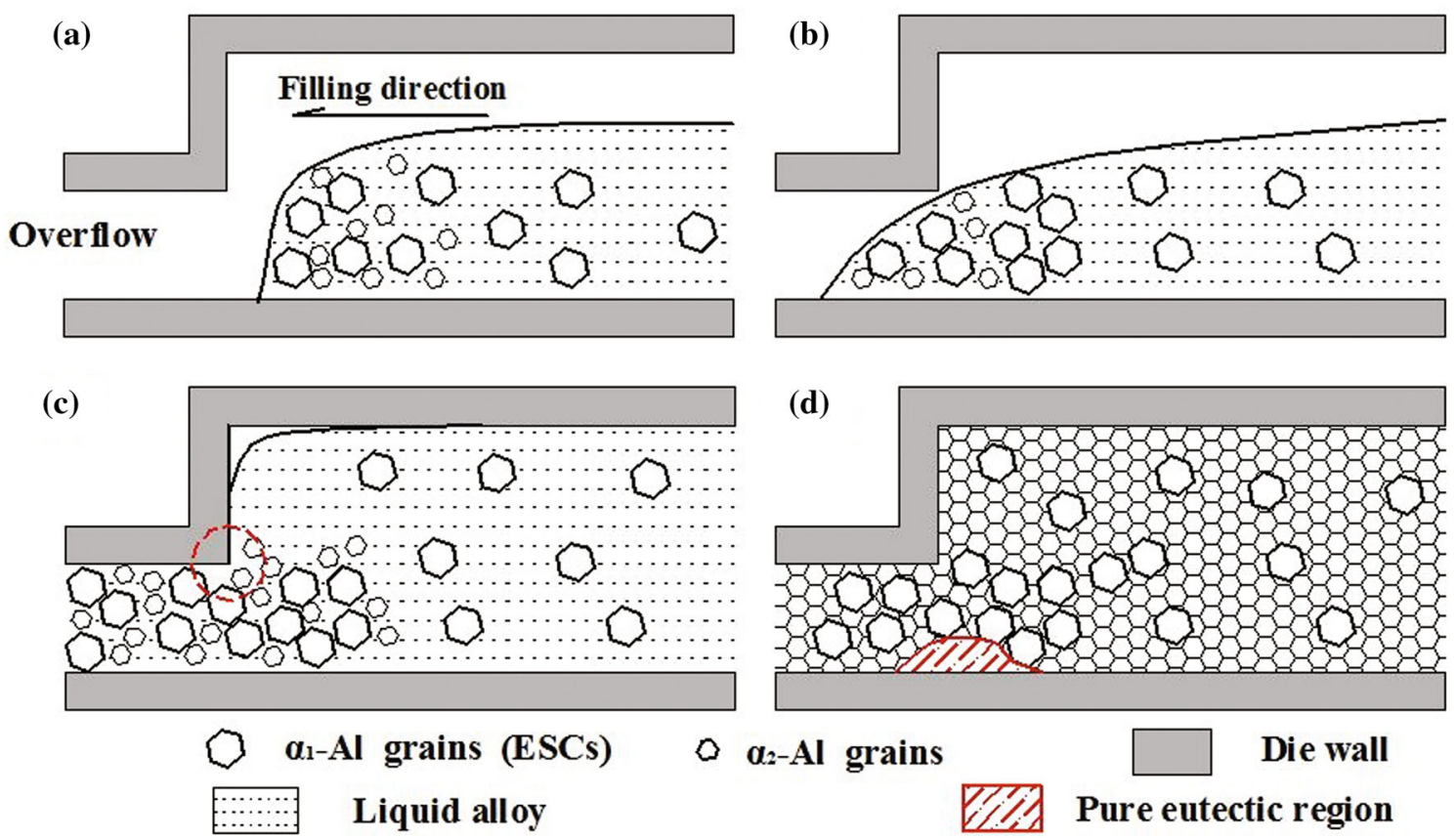

Fig. 9 Schematics of the formation mechanism of the microstructure around the overflows: a melt front advance to the overflow, $\mathbf{b}$ ESCs are blocked around the overflow, $\mathbf{c}$ liquid alloy preferentially solidified around the overflow, $\mathbf{d}$ die-filling process completed

Furthermore, the pure eutectic layer observed in Fig. 5e is closely related to flowing behavior of the residual liquid. A gap between the melt and bottom die is formed as the solidification contraction occurs. Subsequently, the gap is filled by the residual solute-enriched liquid with near eutectic composition through the interdendritic channels. Thus, an almost pure $\left(\mathrm{Al}+\mathrm{Mg}_{2} \mathrm{Si}\right)$ eutectic layer is formed on the bottom die (as shown in Fig. 9d). This phenomenon is a typical inverse macrosegregation which could be promoted by the application of intensification pressure, low gate velocity and low temperature [8]. Moreover, Lee et al. [19] documented that the pure eutectic material at the surface of HPDC AM60 alloy strongly influences the pressure tightness, corrosion and fatigue properties.

\subsection{Vacuum Assistance and Feeding Mechanisms}

In order to evaluate the internal quality and porosity, the densities of the gauge length of B- and C-type specimens are measured by Archimedes method (as listed in Table 4). The density of HVDC-B specimen $\left(2.602 \mathrm{~g} / \mathrm{cm}^{3}\right)$ is slightly higher than that of HPDC-B specimens $\left(2.593 \mathrm{~g} / \mathrm{cm}^{3}\right)$, both of which are significantly lower than that of HPDC-C-type specimens $\left(2.641 \mathrm{~g} / \mathrm{cm}^{3}\right)$. Therefore, HVDC just slightly improved the internal porosity. Moveover, the superior 
Table 4 Comparison of the densities of B and C specimens

\begin{tabular}{llll}
\hline Process specimen & HPDC-B type & HVDC-B type & HPDC-C type \\
\hline Density $\left(\mathrm{g} / \mathrm{cm}^{3}\right)$ & 2.593 & 2.602 & 2.641 \\
\hline
\end{tabular}

density of C-type specimens can be attributed to the effective feeding mechanism.

Because HPDC process has no risers or feeders as compared to other casting processes, thus, most of the feeding liquid must be transported into the die cavity through the ingate. The ingate thickness and intensification pressure (IP) are predominantly responsible for the formation of shear bands and feeding mechanisms [9]. Thus, an appropriate combination of the ingate thickness and IP may lead to bulk deformation of the mush in the gate which often results in shear banding. Substantial feeding liquid can be transported into the die cavity as the shear banding occurs, because the shear banding creates weak zones to reduce the shear resistance and that kind of feeding behavior is mass feeding. With regard to interdendritic feeding, limited feeding liquid flows through the interdendritic channels in the stationary solid networks; thus, interdendritic feeding is far less effective than the mass feeding. Otarawanna et al. [20] have documented that the gate thickness of $2 \mathrm{~mm}$ and IP of $61 \mathrm{MPa}$ lead to mass feeding with regard to the C-type specimens. Feeding liquid is transported into the grip sections and effectively compensates the porosity, whereas the wall thickness of the HPDC plate is $4 \mathrm{~mm}$ which is much smaller than the diameter of the grip section of C-type specimens. Hence, numerous presolidified crystals block the ingate which dramatically impedes bulk deformation and mass feeding; thus, the dominant feeding mechanism of the plate-like samples is interdendritic feeding [9]. Consequently, the ineffective feeding of plate-like samples resulted in the higher porosity, lower density and inferior mechanical performance.

\section{Conclusions}

(1) The microstructure of HPDC $\mathrm{AlMg}_{5} \mathrm{Si}_{2} \mathrm{Mn}$ mainly contains dendritic, spherical $\alpha_{1}-\mathrm{Al}$ grains, fine-size $\alpha_{2}-\mathrm{Al}$ grains and $\left(\mathrm{Al}+\mathrm{Mg}_{2} \mathrm{Si}\right)$ eutectic.

(2) The surface layers with fine-size primary $\alpha-\mathrm{Al}$ crystals are observed in the indirect impingement zones and disappear in direct impingement zones. Ellipse-like surface layer edge is currently observed in the corner of the upper die near the gate. Pure eutectic layers are formed near the overflow because residual solute-enriched liquid with near eutectic composition moves into the gap between the casting and the die.

(3) The backflow of melt is predominantly responsible for the superior mechanical properties of the specimens near the gate. The tensile properties of the plate samples are significantly lower than those of round test bars due to the mass feeding induced by shear banding.

Acknowledgments This work was financially supported by Guangdong Provincial Department of Science and Technology, China (No. 2012A090300016). Authors would like to express thanks to Material Institution of CAEP (China Academy of Engineering Physics). The authors would also like to express their appreciation to the Analytical and Testing Center, Huazhong University of Science and Technology.

\section{References}

[1] D. Brungs, Mater. Des. 18, 285 (1997)

[2] D. Carle, G. Blount, Mater. Des. 20, 267 (1999)

[3] K. Greven, D. Dragulin, in Proceedings of the 2nd International Conference on Light Metals Technology, ed. by H. Kaufmann (LKR-Verlag, Beschreibung, 2005), pp. 19-23

[4] H. Kaufmann, P.J. Uggowitzer, Adv. Eng. Mater. 3, 963 (2001)

[5] H. Kaufmann, P.J. Uggowitzer, Metallurgy and Processing of High-integrity Light Metal Pressure Castings, 1st edn. (Schiele \& Schön, Berlin, 2007), pp. 180-190

[6] S. Ji, D. Watson, Z. Fan, M. White, Mater. Sci. Eng. A 556, 824 (2012)

[7] S. Otarawanna, C.M. Gourlay, H.I. Laukli, A.K. Dahle, Mater. Charact. 60, 1432 (2009)

[8] S. Otarawanna, C.M. Gourlay, H.I. Laukli, A.K. Dahle, Mater. Chem. Phys. 130, 251 (2011)

[9] S. Otarawanna, H.I. Laukli, C.M. Gourlay, A.K. Dahle, Metall. Mater. Trans. A 41, 1836 (2010)

[10] A. Luo, A.K. Sachdev, B.R. Powell, China Foundry 4, 463 (2010)

[11] X.P. Niu, B.H. Hu, I. Pinwill, H. Li, J. Mater. Process. Technol. 105, 119 (2000)

[12] G. Hébert, D. Dubé, R. Tremblay, Mater. Sci. Eng. A 552, 89 (2012)

[13] C.K. Jin, C.G. Kang, Int. J. Hydrogen Energy 37, 1661 (2012)

[14] Z. Hu, L. Wan, S. Wu, H. Wu, X. Liu, Mater. Des. 46, 451 (2013)

[15] Z.W. Chen, Mater. Sci. Eng. A 348, 145 (2003)

[16] A. Hamasaiid, G. Wang, C. Davidson, G. Dour, M.S. Dargusch, Metall. Mater. Trans. A 40, 3056 (2009)

[17] N.A. Belov, D.G. Eskin, A.A. Aksenov, Multicomponent Phase Diagrams: Application for Commercial Aluminum Alloys (Elesvier, Oxford, 2005), pp. 47-82

[18] A.K. Dahle, D.H. StJohn, Acta Mater. 47, 31 (1998)

[19] S.G. Lee, G.R. Patel, A.M. Gokhale, Scr. Mater. 52, 1063 (2005)

[20] S. Otarawanna, C.M. Gourlay, H.I. Laukli, A.K. Dahle, Trans. Indian Inst. Met. 62, 499 (2009) 